\title{
An Experiment Involving Water Source Application and Water Systems in Urban Parks Based on Magok Central Park: Focusing on Water Resources Use and the Water Circulation System in Magok Central Park
}

\author{
Park Hoon \\ Department of Architecture Design, Kangwon National University, 346 Joongang-ro, \\ Samcheok-si, 25913 Gangwondo, Korea
}

\begin{abstract}
Water resource application planning has been contemplated in various ways in Korean society. With an increase in water-related disasters due to climate change, water source application planning has been combined with countermeasures for safety and has been discussed in terms of its usability. In searching for measures that utilize a given environment, urban parks can be expected to play a role as important targets of water source application. Urban parks began as spaces used for the rest and leisure of urban residents and their usage as water spaces has been proactively sought out, in addition to their diversity in design. As examined through this study, their meaning in various aspects can be verified. The conclusion of this study is as follows. This study will review water space application and usage patterns in urban parks and propose new possibilities of utilization through an examination of the Magok Central Park water system. Water systems built in this manner form various unit spaces that utilize water which increases their educational significance and adds value by combining this with plant planning. The experimental significance of Magok Central Park that this study proposes possesses a differentiated significance in that it proactively explores environmental considerations alongside availability through education and first-hand exerience.
\end{abstract}

Key words: Water cycling system, water resources, education, experience, Magok Central Park, society

\section{INTRODUCTION}

Lifestyles and living circumstances in Korean society have rapidly transformed due to industrialization and urbanization that took place over a short period of time. This has also acted as a factor in transforming the natural environment. Recent floods due to increased climate change are elements that symbolically explain this. Water is always around us and is part and parcel to human development. The importance of water utilization is growing as we enter modern society. Urban parks are representative public spaces in cities have increasing functional roles and are important spaces for the relaxation of urban citizens (Sin-Ha and Yeong-Hui, 2012). Continuous strategies are being presented in the categories of landscaping and city planning. Since, the 1950 's, large-scale urban parks have been constructed including the Children's Grand Park (1973), Olympic Park (1984), Yeouido Park (1996), Ilsan Lake Park (1996), Seoul World Cup Park (2002), West Seoul Lake Park (2009) and the Dream Forest (2009). These present meaningful implications in our urban parks (Anonymous, 2015). Parks like these include lakes, ponds and other water spaces in various forms and sizes and their usability is gradually rising (Seung-Bin et al., 2014; Eun-Yeong et al., 2014). As such, this study examines the various application characteristics of water sources in urban parks which are typical green spaces in cities and presents experimental proposals for water systems based on real park planning.

\section{Theoretical considerations}

The growth and characteristics of urban park planning: After the industrial revolution, the concepts of citizens and the public came to the fore. As parks were opened to the general public, they gradually became places for public use. Parks became public parks. Urban parks can be traced back to the ancient Greek and Roman periods. The agora which holds significance as a public place is derived from the forum. During the historical development process, the personal gardens that monarchs of the West owned were transformed into public domains for the general population and played the roles of resting places based on the landscapes of the countryside (Park, 2015). Later, modern urban parks, starting with New York's Central Park, reflected design patterns based on various technologies and models alongside the growth of cities and grew based on design strategies that took the environment and regional conditions into consideration. The main spaces are composed of green spaces and water spaces that are characteristic of parks, forest spaces centered on trees and bushes and grass plazas formed from spacious grasslands. These form the main spaces 
based on the surrounding urban environment, spatial system of the main spaces and the movement patterns of its users. These create a park-planning concept centered around a forest, grass area and lake based on the directionality of the park.

\section{MATERIALS AND METHODS}

Application and utilization of water space: The water space in a park is founded on diversity. Along with the growth of modern cities, tap water, recycled water and reclaimed water are highly important for the environment and usable water of a park and have a relationship with the usage plans of the surrounding space (Jang et al., 2002). Water space planning in the various green spaces that we have experienced is based on these ideas which allows users to have a sense of psychological stability and comfort. The typical spaces constructed through this include lakes, ponds and streamlets which provide a habitat for animals and plants in the park and also, perform the role of creating an aquatic ecosystem. These perform important roles as habitats for various wild plants and animals in one biotope. Biotopes differ from habitats which point to the habitation locations for individual organisms and refer to a spatial unit that helps wildlife habitations and movement (Ministry of Environment, 1995). By creating ecological water spaces, biotopes provide habitation spaces for plants and animals that are disappearing which increases species diversity and plays an important role in improving the overall urban ecosystem (Park, 2017). Ecological parks that reflect these kinds of spaces raise the maintenance of ecological parallelism and the improvement of human living environments as important issues, maintain the balance between oxygen and carbon dioxide, purify harmful airborne substances, reduce noise and regulate the climate (U-Il, 2006). They also raise the important issue of providing food and resting places for birds and insects. The ecological function of parks is gradually being applied as an essential element in urban parks and the Magok Central Park examined in this study is also taking on an ecological meaning (Table 1).

Table 1: Water application types in water spaces

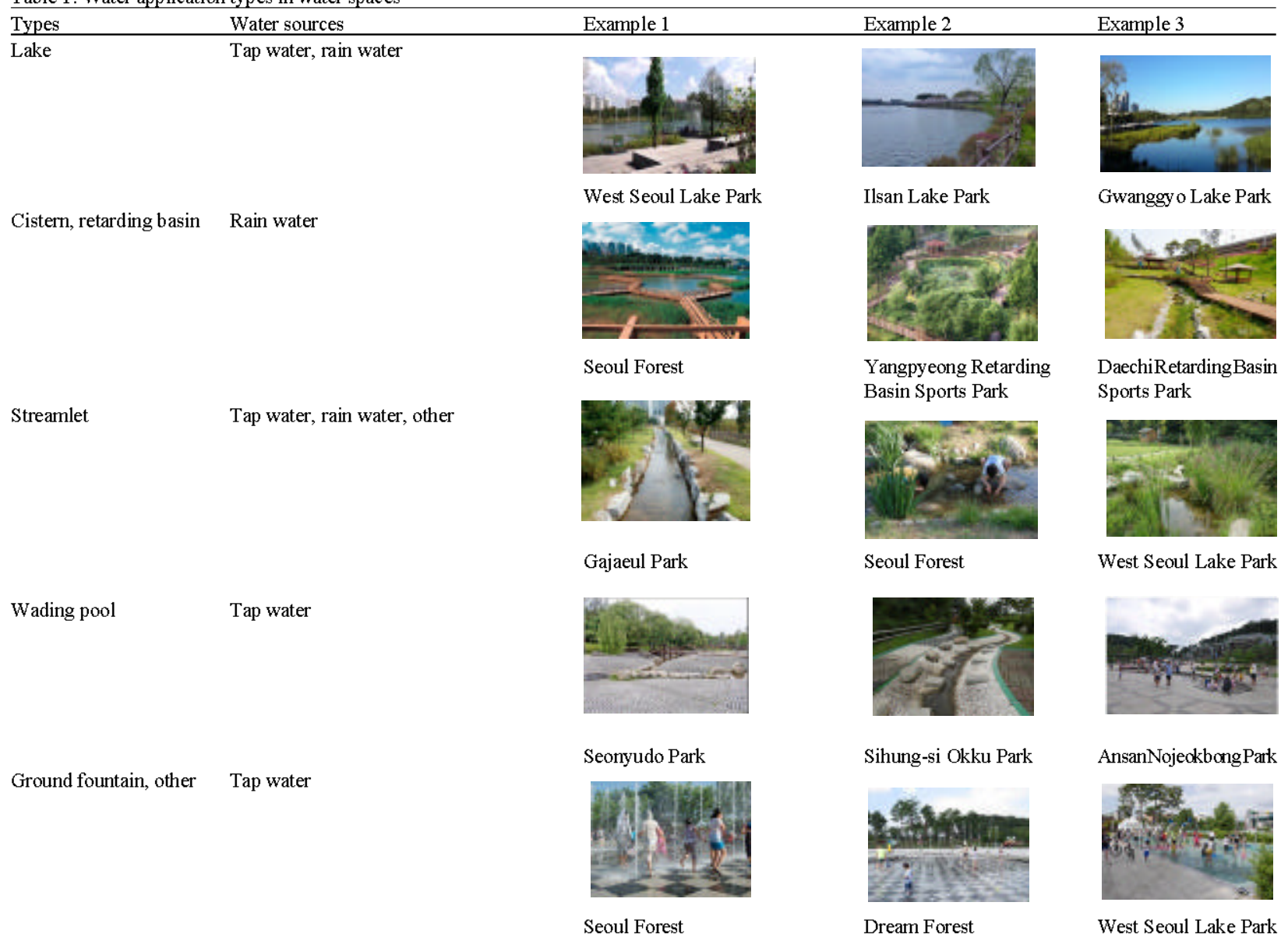

Field survey by the researcher (03-2017 to 06-2017) 


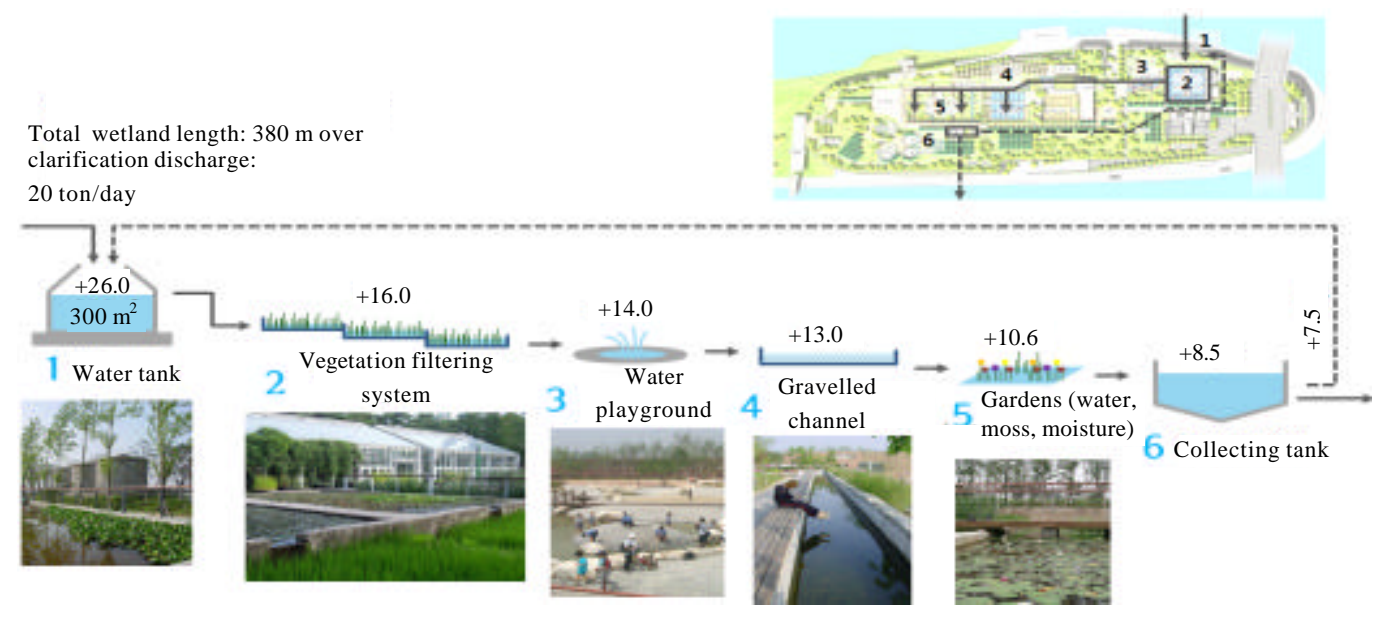

Fig. 1: Seonyudo Park's plant purification process and estimated purification treatment rate

Application of the water cycling system: The following can be verified when proactively utilizing water spaces. The Seonyudo Park was formerly used as a filtration plant for the Han River. Beginning in 2002, it was redesigned and opened as a park and its filtration facilities were recycled and made into ecological and aquatic life spaces (Tae-Yun and Gyeong-Lim, 2006). The park was made into a plant park and plant purification area based on available water. The total area of the park is 114 thous. $\mathrm{m}^{2}$ and the main facilities within the park include a greenhouse comprised of two buildings, a garden of green columns, an aquatic botanical garden, the garden of time and the environmental water playground. The park also possesses a vegetation environment. Designing land organism plants increases effectiveness through the mutual relationship of trees, bushes and grass fields and the park has planted 48 species of trees including willow, birch and water trees as well as 30 species of bushes including fruit trees and 125 types of flowers and grasses including reeds, cattails and thyme. These kinds of plants form an abundant park space and improve the ecological environment and climate (Sang-Don, 2010). Plant environments like this are connected to water cycling systems to create a differentiated space. Also, concerning the levels of main spaces in Seonyudo Park, the highest facility is the water tank. From $26 \mathrm{~m}$ height to $8.5 \mathrm{~m}$ height where the water tank is located, the water system is formed by using the level differences of main spaces. The total length of the water system is over $380 \mathrm{~m}$ and purification treatment is done along the main spaces such as purification plants and swimming space (wading pools).

The water space plan in Seonyudo Park comprises various design methodologies. Planning that utilizes hydroponic facilities such as the one above has various design approaches based on water quantity and water sources. When the researcher analyzed this, a total amount of 20 tons/day was predicted to be possible for purification treatment. In an educational sense, through the experiences of users who have experienced existing ecological parks, this increases and secures the potential of water purification through aquatic plants and can be proactively explained as an example that explores the utilization of this as an educational space. Purification through plants has significant meaning as an environment-friendly landscape architecture plan (Fig. 1).

\section{RESULTS AND DISCUSSION}

The experimental application of Magok Central Park Premise of the plan: Magok Central Park was based on past waterfront plans and was transformed to an urban-style botanical garden using plants and water. It is significant as the only place in Seoul that performed rice farming until 2000. The various types of water sources and water spaces that have appeared with modern society such as storage spaces provided for surrounding urban and transportation development as well as flood controls for the Han River are important for the growth of Magok Central Park into a specialized space that utilizes water (Park, 2016). Another domain of botanical gardens involves building up the topography through mounding which also provides advantages in the utilization of water sources. Regarding topographic levels formed through this, the level of EL is $+14 \mathrm{~m}$ that of the lake is $+2 \mathrm{~m}$ and that of the retarding basin and detention pond is $0 \mathrm{~m}$ and different levels in different areas are used to be equipped with the water cycling system. In this manner, the park attempted to plant various aquatic plants through a space where the natural and manmade topographies were balanced on the basis of planned characteristics in which water was purified. Aside from the difference of height, 


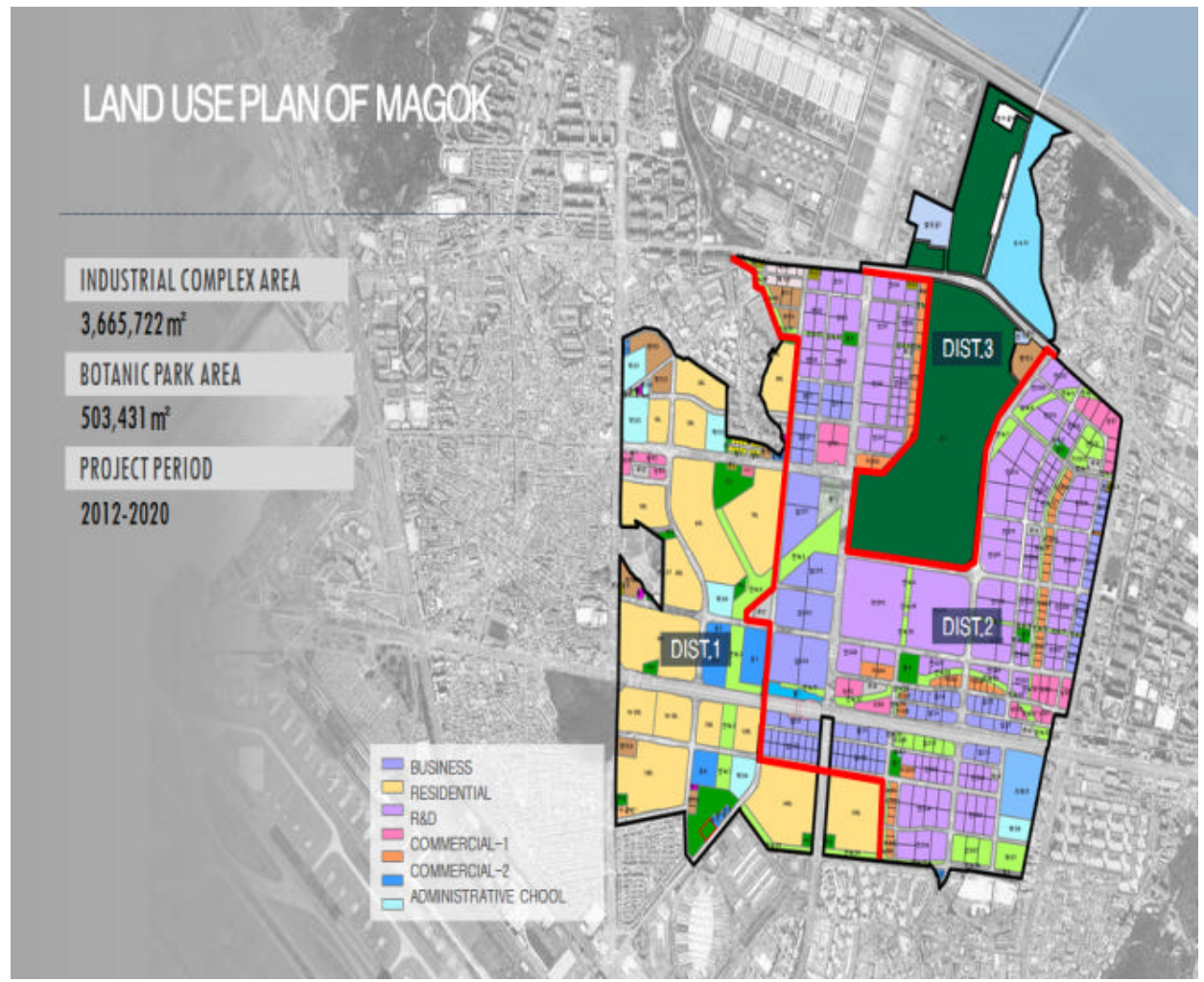

Fig. 2: Magok land use plan

natural purification is also induced by using aquatic plants, water plants and purification plants. This plays roles in heightening the meaning of Magok Central Park. Magok is in fact, an area that has remained underdeveloped in Seoul for a long period. Through a large-scale urban development project, development started. District 1 is supposed to be the housing complex while District 2 will be the industrial complex. Magok Central Park, the subject of this study, belongs to District 3. Its area is up to $503,431 \mathrm{~m}^{2}$ (Fig. 2).

Design strategy: Magok Central Park builds up its topography around the botanical garden area. This performs the role of creating unit landscapes that are differentiated from the entire territory. The park builds an ecology park centered around the detention pond as well as a retarding basin to the north of Yangcheon-gil and strengthens connectivity with the Han River. A lake park was built on the left side of the park, creating an urban atmosphere. To the right of this are the botanical gardens which perform the central role of Magok Central Park (Tae-Yun and Gyeong-Lim, 2006). To the South is the green field which provides an open space to experience various cultural events in the urban park. To this end, the design concept of the park materialized into one in which the park developed as land for flood control and which also displayed the landscape of the old Han riverfront. Overall park planning as shown in Fig. 3, takes place through zoning plans that include the creation of topography and primary programs that are the foundation of parks. This performs the role of a cycling system for water sources and is a model of proactive water source application.

Magok Central Park consists of 4 areas and each area is formed around the theme space. Particularly, as the main spaces related to the water cycling system, the square leading to the open forest park, lake in the lake park, waterside rest area, waterside tree-lined streets, the retarding basin of the wetland eco-park, detention ponds, the gardening culture experience center in the botanical garden, theme garden and the forest culture center have roles as main spaces (Fig. 3).

Water source application: The usable water sources and water quantities in the Magok District are as follows. Seven water sources, starting with tap water, explain the area's environmental characteristics (Park, 2016). Regional characteristics including abundant water in the past and reclaimed water from a sewage treatment center that was built in the process of urban development, effluent groundwater that occurs in subway construction 


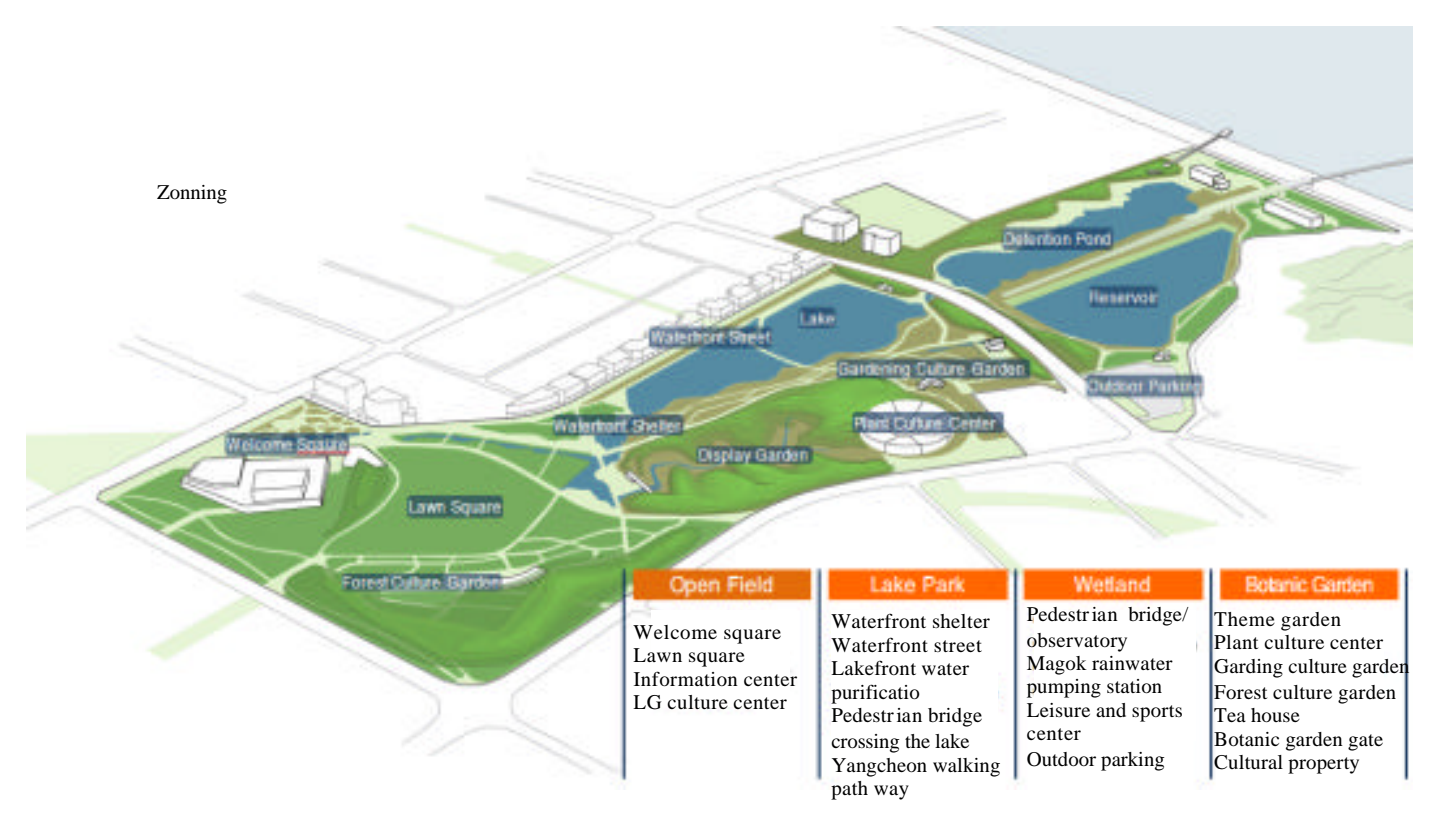

Fig. 3: Magok Central Park master plan

Table 2: Magok District usable water sources and characteristics

\begin{tabular}{|c|c|c|c|c|}
\hline Classification & Water quantity & Minimum water quality & Cost & Characteristics \\
\hline Water supply & No limit & Grade $1 b$ & 840 won $/ \mathrm{m}^{3}$ & $\begin{array}{l}\text { Abundant quantity of water } \\
\text { Good water quality } \\
\text { Water maintenance costs incurred (high price) }\end{array}$ \\
\hline Water source & No limit & Grade 4 & 393 won $/ \mathrm{m}^{3}$ & $\begin{array}{l}\text { Abundant quantity of water } \\
\text { Satisfactory water quality } \\
\text { Water maintenance costs incurred }\end{array}$ \\
\hline Rainwater utilization & Uncertain & - & Free & $\begin{array}{l}\text { Uncertain water quantity (no regular water source) } \\
\text { Unverified water quality } \\
\text { Plans to use individual plots }\end{array}$ \\
\hline $\begin{array}{l}\text { Southwest STP advanced } \\
\text { wastewater treatment }\end{array}$ & $1,630,000 \mathrm{~m}^{3} /$ day & Grade 6 & Free & $\begin{array}{l}\text { Abundant quantity of water } \\
\text { Usable during water treatment (very poor water } \\
\text { quality) }\end{array}$ \\
\hline Subway water discharge & $\begin{array}{l}689 \mathrm{~m}^{3} / \text { day (one place } \\
\text { outside Magok station) }\end{array}$ & Grade 3 & Free & $\begin{array}{l}\text { Make-up water quantity level } \\
\text { Satisfactory water quality conditions (excluding } \\
\text { nitrogen) } \\
\text { Temporary deterioration of water quality when } \\
\text { cleaning subway } \\
\text { Concern of floration due to iron components }\end{array}$ \\
\hline Han River water & No limit & Grade 6 & Free & $\begin{array}{l}\text { Abundant quantity of water } \\
\text { Usable during water treatment }\end{array}$ \\
\hline Southwest STP reclaimed water & $20,000 \mathrm{~m}^{3} /$ day & Grade 6 & Free & $\begin{array}{l}\text { Poor water quality (beyond recreation water) } \\
\text { Reclaimed water resources }\end{array}$ \\
\hline
\end{tabular}

sites due to urban development and usable water from the Han River are the representative water sources in this area (Table 2). The usable water quantities and required costs of water sources such as these as well as the characteristics of the water quality were differentiated and taken into consideration to examine their potential application in park planning.

\section{Application by field}

Application in park structures: Water cycling systems used in the greenhouses of Magok Central Park are shown in Fig. 4. It was intended to utilize a variety of water sources corresponding to the basic concept of Magok Central Park. Basic data associated with this such as water quantity are grounded on the contents suggested in related reports. Based on that, water quantity and the total amount of water sources consumed in buildings were estimated. The greenhouses in Magok that use Han River water, tap water, treated wastewater and rain water as water sources consider the use of these sources for water in washing bathrooms, face-washing water and landscape trees. Greenhouses are based on 


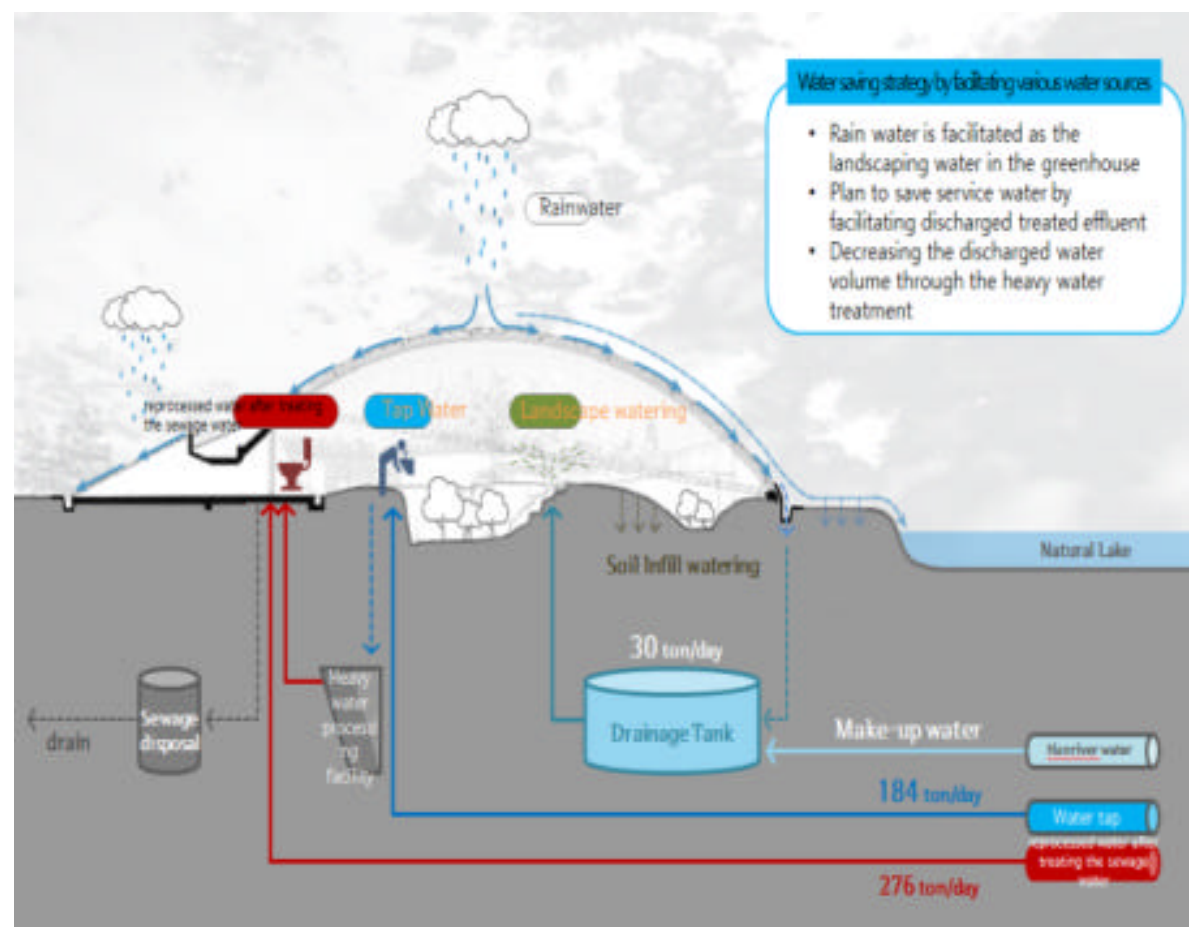

Fig. 4: Proposed water cycling system for greenhouse structures in Magok Central Park

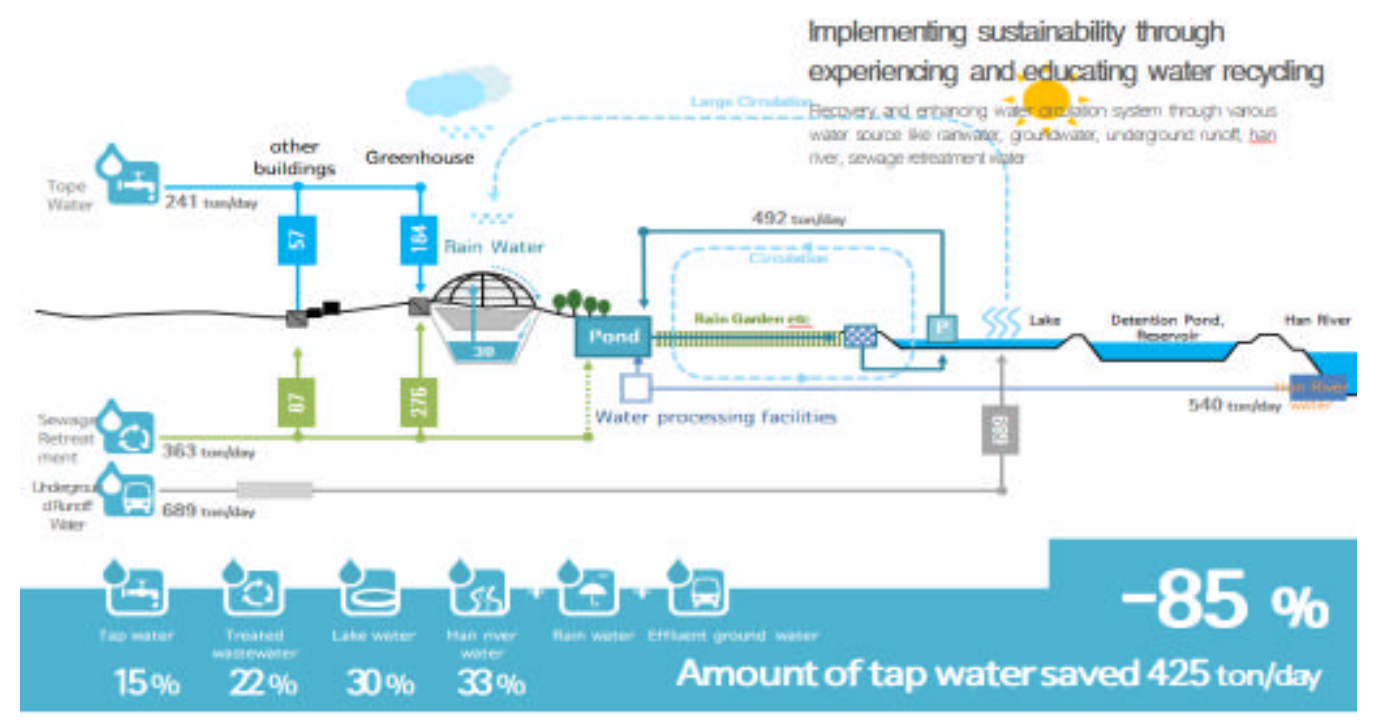

Fig. 5: The Magok Central Park water cycling system concept

environmentally friendly planning and place importance on planning characteristics that proactively utilize the various water sources that are aimed for at Magok Central Park. Rainwater is collected to be reclaimed by using building structures and treated wastewater supplied in the Southwestern sewage treatment plant uses 275 tons daily which cuts down on tap water utilization in park buildings. Also, water is used as 184 tons a day. The water from the Han River is used as make-up water. These facilities are utilized through various facilities inside the greenhouse and it goes through the recycling process. A plan is carried out that makes the recycling of all water sources possible by utilizing heavy water treatment facilities at the bottoms of buildings and rainwater detention facilities.

Application of the park water cycling system: The water cycling system located in Magok Central Park is shown in Fig. 5. The various water spaces planned in Magok 


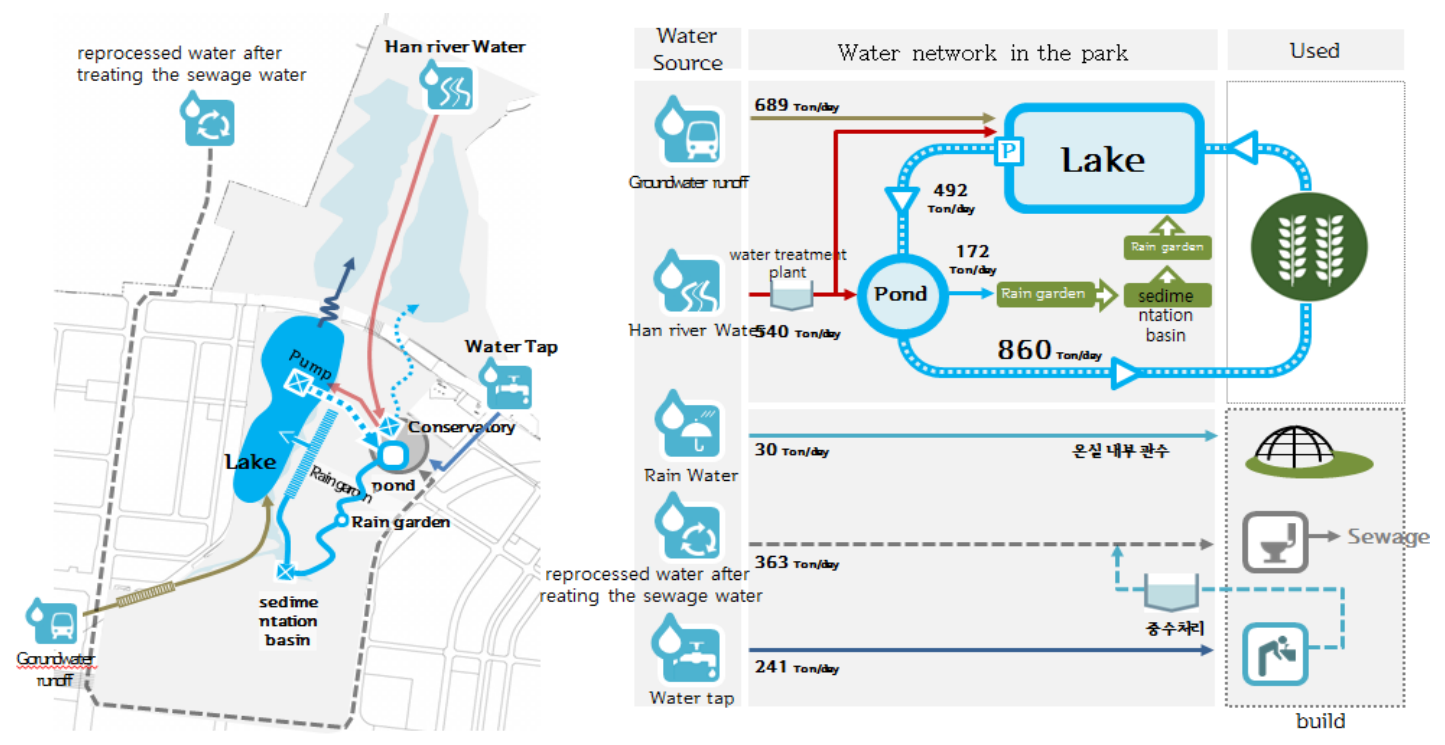

Fig. 6: Round-up of Magok Central Park's water system

Central Park including a marsh, treatment wetland, lake, retarding basin and detention pond are arranged in 4 primary domains and are connected to a water source provided through the adjacent Han River. This adds to the importance of the overall water system. Also, developing a water system that possesses a lesser circulation and general circulation structure achieves the foundation of environment-friendly planning. This kind of approach is also reflected as a plan that saves $80 \%$ of tap water for existing dry environment provisions and is applied as a plan that saves 1,425 tons of water per day. The section that forms the treatment wetland in the portion that is connected from the marsh to the lake possesses educational meaning because it purifies treated wastewater through plants and its diverse aquatic plants form a large landscape that can be experienced from urban spaces on the opposite side of the lake. Aquatic plants, in addition to their role as natural environmental elements, also possess a function that performs natural purification. In addition, they directly carry out the role of materializing plans such as these throughout the entirety of the park. Meanwhile, the irrigation capacity required across the park is estimated at 350 tons.

Round-up: The water system used in Magok Central Park can be organized as shown in Fig. 6 . The 5 primary water sources (i.e., effluent groundwater, Han River water, rain water, treated wastewater and tap water) are applied to the park's four primary spaces (i.e., the lake park, forest park, botanical gardens and wetland eco-park) in various ways and display a unique landscape that has been planned in such a way for the user's experience. The water of the Magok District involves a plan that coincides with a spatial environment that reflects many regional characteristics and an educational concept is applied through water. Plans that comprehensively utilize structures such as external spaces and greenhouses add to the importance of the overall water system. The proactive use of various water resources for procuring sustainability as attempted through water resources, the repeated use of water sources through general circulation and lesser circulation structures, water source application strategies and the planning characteristics of Magok Central Park that apply a potential resource application by using recyclable water are distinct from existing park planning.

\section{CONCLUSION}

In addition, to urban development, urban parks that have developed through the application of various design techniques have achieved tremendous growth in terms of design strategies and aspects and have increased in importance as amenity spaces for citizens. Magok Central Park was examined through this study and possesses significance as a park plan that captures value through the application and utilization of water resources from various aspects. The conclusion of this study is as follows. First, the urban park proactively reflects the various water resources that the Magok District possesses. This includes a diversity of sources such as tap water, Han River water, treated wastewater, effluent 
ground water, lake water and marsh water. Second, the park explores the potential of plant planning via. water sources which performs the role of providing an educational space within the park. This also strengthens natural purification functions via aquatic plants which bestow an educational role throughout the entirety of the park. Third, various water sources allow users to procure diversity in terms of the methods by which water sources are utilized. This diversity is procured from the water we touch to the water we view as scenery. Regarding plant planning in particular, building a landscape in the park is of significance. Fourth, expanding on experiences via existing water sources, water source utilization measures for educational purposes have been proactively explored and proactive examinations of natural purification methods via aquatic plants are a forward-looking planning approach that expands on existing water source uses.

\section{REFERENCES}

Anonymous, 2015. [Seoul's mountain park program]. Seoul Metropolitan Government, Seoul, South Korea. (In Korean)

Eun-Yeong, K., L. Jeong-Ah, K. Hyeong-Gon and J. Jin-Hyeong, 2014. A study on urban Eco park user characteristics Kildong Eco park, Yeouido Saetgang Eco park. J. Korean Landscape Stud., 42: 64-74.

Jang, B.G., L.Y. Sung, S.Y. Lee, J.E. Kim and S.J. Lee, 2002. A study on design method of water space in ecological park-focused on the ecological park in Seoul. J. KIEAE., 2: 49-56.
Park, H., 2015. The basic plan for Magok central park and its significance as a modern urban park. Urban Des., 16: $105-122$.

Park, H., 2016. Assessment of the Magok district urban development project using urban vitalization theory of growth management. Proceedings of the International Conference on Sustainable Built Environment SBE16, December 11-14, 2016, The K-Hotel, Seoul, South Korea, pp: 1-24.

Park, H., 2017. An experimental study on the use of water sources and water system in urban park. Intl. J. ICT. Aided Archit. Civil Eng., 5: 1-6.

Sang-Don, L., 2010. A study on the development of the ecosystem environment and Eco park in Anyang stream and the surrounding area. Korean J. Wetland Res., 12: 145-153.

Seung-Bin, L., K. Yun-Gu, J. Yun-Hui, H. Yun-Seon and B. Jae-Sang, 2014. The creation of Seoul forest as a reproduction of place memories: A study on the placeness formation structure of Seonyudo Park. J. Korean Landscape Stud., 42: 1-12.

Sin-Ha, J. and K. Yeong-Hui, 2012. Awareness level of design concepts among urban park users Seoul Forest Park, Yeouido Park, Seonyudo Park. J. Korean Landscape Stud., 38: 53-63.

Tae-Yun, P. and N. Gyeong-Lim, 2006. Demand survey on Eco park creation and eco education programs. Korean Soc. Environ. Restor. Revegetation Technol., 9: 95-106.

U-Il, B., 2006. A study on pond detention Eco park design models. Korean Soc. Environ. Restor. Revegetation Technol., 9: 1-16. 